\title{
IMPROVING THE STRUCTURAL BEHAVIOUR RC PRECAST CONCRETE BEAMS MADE OF RECYCLED AGGREGATE CONCRETE
}

\author{
Andrzej LAPKO, Robert GRYGO \\ Department of Building Structures, Bialystok University of Technology, \\ Wiejska 45A, 15-351 Białystok, Poland
}

Received 12 Sep 2013; accepted 08 Oct 2014

\begin{abstract}
The application of concrete waste for recycled aggregate concrete (RAC) used in structural members is associated with an increased risk for the structure due to, e.g. pollutions in the old crushed concrete and random variable strength. A new concept of RC flexural members like beams and slabs made of RAC with strengthening inclusion was elaborated and presented in the paper based on application of precast concrete inserts made of HSC, located in the compression zone of the members. The paper presents the results of experimental and numerical (FEM) analysis carried out on such composite beams. The results of experimental research on the behavior of such beams and numerical simulations using Diana computer program reveal some positive effects, such as higher stiffness and flexural capacity of the innovative beams compared to the reference beams made fully of RAC.
\end{abstract}

Keywords: innovative constructions, RC beams, recycled aggregate concrete, strengthening inclusions, HSC.

\section{Introduction}

For several years construction debris has been put to use, usually as a road base or for levelling the ground. It would be a better solution would be to use such recycled aggregate to produce concrete structures.

One of the possible uses of recycled concrete in the $\mathrm{RC}$ constructions is to replacing natural aggregate with the recycled aggregate. It is estimated, that the global world concrete construction industry needs a huge volume of natural aggregates (about 10 billion ton per year).

The research on structural members made of recycled aggregate concrete (RAC) has been conducted since the 90s in many countries. In 1994, in Osnabruck, Germany the first apartment building was constructed with recycled aggregate concrete (Roos 2002). The problems with the use of secondary concrete aggregates for constructions have recently been considered in a few publications (Ajdukiewicz, Kliszczewicz 2007, 2012; Shayan, Xu 2003; Cassuccio et al. 2008; Murali et al. 2012; Ho et al. 2013). The problem of application of coarse ceramic waste for structural concrete has recently been analysed in Poland from construction industry perspective (Domski, Katzer 2013).

The carrying capacity and stiffness of flexural members made of RAC results mainly from the tensile reinforcement and the concrete compression zone, which depend on random compressive strength variable of the recycled aggregate concrete (Xiao et al. 2007). Previous studies (Rahal 2007; Sagoe-Crentsil et al. 2001; Maruyama et al. 2004; Shayan, Xu 2003; Limbachiva et al. 2004; Jeske et al. 2004) showed that the application of concrete waste for recycled aggregate concrete used in structural members is associated with an increased risk for the building structures. The designers are probably afraid of wider application of RAC as structural concrete (Jeske et al. 2004; Yadav, Pathak et al. 2009; Gilbert, Kilpatrick 2011; Malešev et al. 2010).

On the basis of results of own experimental studies on model beams (Lapko et al. 2005; Lapko, Grygo 2010, 2011, 2013; Grygo et al. 2011) some significant differences in the behavior of flexural structural elements made of recycled aggregate concrete (RAC) were confirmed, compared to members made of concrete with natural aggregate. The beams made of RAC cracked earlier and showed greater deflections under comparable loads. The concrete strains in the most stressed compression zone of such beams were higher by about $45 \%$ of the strains in the reference beams made of natural aggregate concrete, whereas the mean values of strains in the tension zone were comparable.

$\mathrm{RC}$ beams made of RAC showed lower flexural capacity of 5 to $7 \%$, compared to reference beams made of natural aggregate concrete with similar class of compressive strength. There were no differences observed in the mechanism of destruction, all the beams were destroyed as expected, by the yielding of the reinforcement in the tension zone. 
To avoid some risks for the structural behavior of members made of recycled aggregate concrete the authors proposed an innovative solution for constructing $\mathrm{RC}$ flexural members made of RAC prepared with an inclusion (being a kind of inserts) made of High Strength Concrete (HSC) located in the most compression zone of the RC member (Lapko, Grygo 2013).

This paper describes the results of experimental and numerical studies of such innovative constructions based on the tests on model and full-scale RC beams conducted by the research team of the Chair of Building Structures of Bialystok University of Technology.

\section{Description of the innovative beams made of RAC}

\subsection{The conception and materials used}

The concept of an innovative RC beam structure made of recycling aggregate concrete is based on an application of thin layered precast concrete strengthening HSC inserts with the compression strength $f_{c k} \approx 100 \mathrm{MPa}$ on the basis of good quality natural aggregate. During the construction the precast HSC insert is located in the central part of compressive zone of a structural member (like simply supported beam or slab) and it is jointed with an arrangement of steel reinforcement (top flexural bars and vertical stirrups). Then the complex system is located in the form and casted with recycled aggregate concrete (RAC). After the hardening process of concrete the HSC insert is durable connected with surrounding recycled aggregate concrete and assured against slipping at the connected horizontal surfaces.

The constructional scheme of the innovated flexural structure is shown in Figure 1. The technological idea of construction has been registered in the Polish Patent Office (Lapko et al. 2009).

Considering the above-mentioned assumptions and results of our pilot studies (Lapko, Grygo 2011) few series of prototype innovative model and also full-scale beams made of recycled aggregate concrete (RAC) with the HSC insert were analyzed theoretically and tested experimentally till the failure. Also two kinds of reference beams fully made of RAC and natural aggregate concrete with similar strength for compression were tested and the results were compared. The characteristics of mix compositions and chosen properties of RAC and normal concrete used in this research are presented in the Table 1 and the properties of $\mathrm{HSC}$ used in the strengthening inserts are presented in the Table 2.

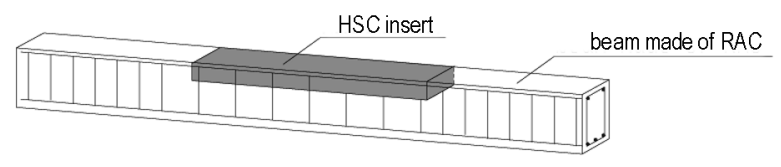

Fig. 1. Technological scheme of an innovative RC beam with the insert made of HSC
The coarse recycled aggregate has been manufactured from demolished 30-year old RC structures with the compression strength $32.4 \mathrm{MPa}$ with mean density of $2440 \mathrm{~kg} / \mathrm{m}^{3}$ and the mean absorbability $6.98 \%$.

In the mix of RAC the coarse aggregate has been only replaced by secondary aggregate, as presented in Table 1.

The secondary aggregate was classified as type II in accordance with RILEM requirements (RILEM 1994).

Table 1. Data composition of recycled aggregate concrete and natural aggregate concrete $(\mathrm{w} / \mathrm{c}=0.7)$ used in tested beams

\begin{tabular}{|c|c|c|c|c|c|c|c|}
\hline \multirow{2}{*}{$\mathrm{V} \mathrm{c}$} & \multirow{2}{*}{$\mathrm{w} / \mathrm{c}$} & \multirow{2}{*}{$\begin{array}{c}\text { Cement } \\
{[\mathrm{kg}]}\end{array}$} & \multirow{2}{*}{$\begin{array}{c}\text { Water } \\
{[l]}\end{array}$} & \multirow{2}{*}{$\begin{array}{c}\text { Sand } \\
{[\mathrm{kg}]} \\
(0-2 \\
\mathrm{mm})\end{array}$} & \multicolumn{3}{|c|}{$\begin{array}{c}\text { Coarse aggregate } \\
{[\mathrm{kg}]}\end{array}$} \\
\hline & & & & & $\begin{array}{l}2-4 \\
\mathrm{~mm}\end{array}$ & $\begin{array}{l}4-8 \\
\mathrm{~mm}\end{array}$ & $\begin{array}{c}8-16 \\
\mathrm{~mm}\end{array}$ \\
\hline RAC & 0.70 & 270 & 189 & 575 & $175^{*}$ & $359^{*}$ & $706^{*}$ \\
\hline $\begin{array}{l}\text { Natural } \\
\text { aggregate } \\
\text { concrete }\end{array}$ & 0.70 & 270 & 189 & 575 & 175 & 359 & 706 \\
\hline
\end{tabular}

Note: *denotes coarse recycled aggregate.

Table 2. Data composition and properties of HSC used in the strengthening insert of innovative beams

\begin{tabular}{|c|c|c|c|c|c|c|}
\hline \multirow{2}{*}{ Series } & \multicolumn{4}{|c|}{ Composition of HSC } & \multirow{2}{*}{$\begin{array}{c}\text { Type of } \\
\text { aggregate }\end{array}$} & \multirow{2}{*}{$\begin{array}{l}\text { Mean } \\
\text { strength } \\
\text { of HSC } \\
{[\mathrm{MPa}]}\end{array}$} \\
\hline & $\mathrm{w} / \mathrm{c}$ & $\mathrm{k} / \mathrm{c}$ & $\mathrm{m} / \mathrm{c}$ & Density & & \\
\hline Series 1 & 0.31 & 3.62 & 0.1 & 2.57 & Basalt & 112.7 \\
\hline Series 2 & 0.29 & 3.66 & 0.1 & 2.53 & Basalt & 115.9 \\
\hline Series 3 & 0.30 & 3.66 & 0.1 & 2.54 & Basalt & 98.0 \\
\hline
\end{tabular}

The compressive strength of the recycled aggregate concrete used in the innovative beams (RH type), as well in the reference homogeneous beams (R type) were evaluated from the tests on samples: $f_{\text {cm, cube }}=32.5 \mathrm{MPa}$ and modulus of elasticity: $E_{c m, r e c}=27.2 \mathrm{GPa}$, whereas for the natural aggregate concrete used in the reference homogenous beams ( $\mathrm{N}$ type): $f_{\text {cm, cube }}=34.2 \mathrm{MPa}$ and modulus of elasticity $E_{c m, n}=30.8 \mathrm{GPa}$. Recycled aggregate concrete mixes were made with different compositions of cement content and $\mathrm{w} / \mathrm{c}$ ratio. The results of compressive strength tests are shown in Figure 2.

For the verification of the results statistical analyses were carried out of the uncertainty of the results of

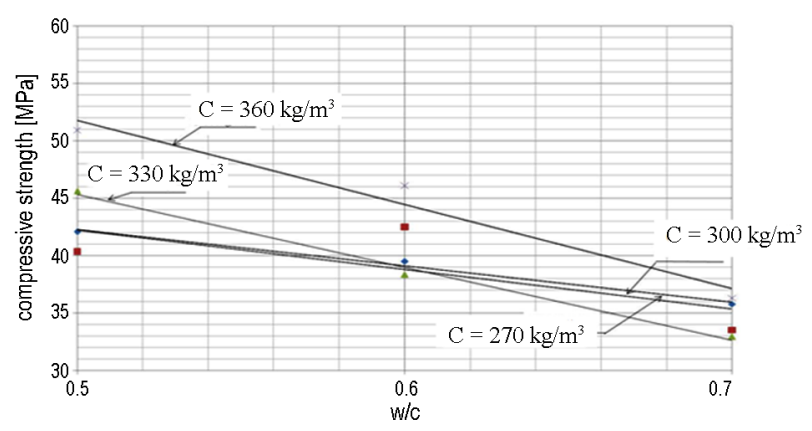

Fig. 2. Compressive strength $[\mathrm{MPa}]$ versus $\mathrm{w} / \mathrm{c}$ ratio diagrams 
strength tests. The standard deviations determined using a development of the $\mathrm{F}\left(x_{i}\right)$ function in a Taylor series with correlated $x_{i}, x_{k}$ input sizes using the Eqn (1):

$$
\begin{aligned}
u_{c}(y)= & \sqrt{\sum_{i=1}^{N}\left(\frac{\delta y}{\delta x_{i}}\right)} \cdot u^{2}\left(x_{i}\right)+ \\
& 2 \sum_{i=1}^{N-1} \sum_{k=i+1}^{N}\left(\frac{\delta y}{\delta x_{i}}\right)\left(\frac{\delta y}{\delta x_{k}}\right) u\left(x_{i}, x_{k}\right) .
\end{aligned}
$$

The $\mathrm{w} / \mathrm{c}$ ratio $=0.7$ for $\mathrm{RAC}$ was assumed to assure good workability of concrete mixes used in the preparation of RC beams with dense arrangement of reinforcing bars. However the high value of $\mathrm{w} / \mathrm{c}=0.7 \mathrm{did}$ not significantly influence the resulting mean values of compressive strength.

The flexural strength of recycled aggregate concrete was also tested. The tensile strength of RAC, compared to the reference natural aggregate concrete was lower only $6.8 \%$.

\subsection{Tests on shrinkage strains}

Tensile stresses are induced in the concrete member due to shrinkage under drying conditions. For the needs of evaluation of shrinkage strains prisms made of two different concretes were prepared: RAC $\left(f_{c m}=28.7 \mathrm{MPa}\right)$ joined with $\operatorname{HSC}\left(f_{c m}=104.3 \mathrm{MPa}\right)$. Schematic layout of the measurement points is presented in Figure 3. The shrinkage strains were measured on the surface of such concrete prism with Demec extensometer in the course 365 days.

In Figure 4 there diagrams of shrinkage strains for tested samples are presented. The red line indicates

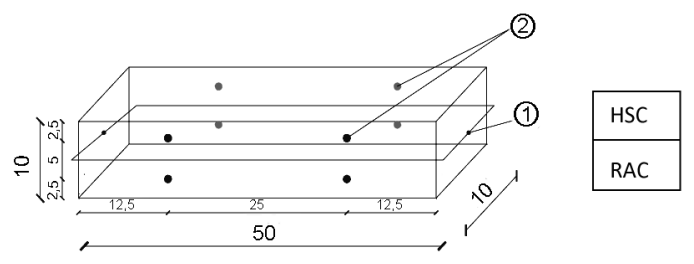

Fig. 3. View of composite prism for measuring of shrinkage strains: (1) measuring points of Amsler Apparatus;

(2) measuring points of extensometer Demec

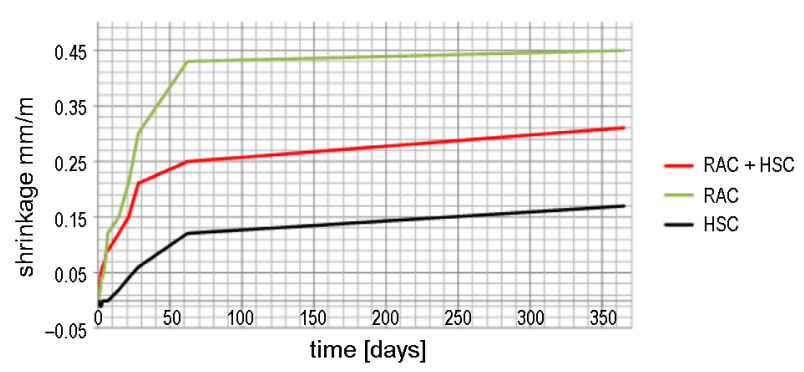

Fig. 4. Shrinkage strains measured during 365 days for three different types of prisms used in the tests changes of shrinkage strains of the concrete prisms made of RAC and HSC. Such concrete prism revealed reduced shrinkage strains compared to the reference prism fully made of RAC. It means that the interface between RAC and HSC should have a positive impact on reducing longterm strains and deflections in RC beams made of RAC with HSC insert. However the shrinkage strains were larger than for reference prism made of HSC.

\section{Studies on full scale innovative beams}

\subsection{Dimensional analysis of innovative beams}

To clarify the scale effect on the structural behaviour of full-scale innovative beams a wide program of experimental tests and computer MES simulations were conducted on the series of above- described beams made of recycled aggregate concrete with the HSC inserts under short time and also long term load. The structure of innovative full-scale beams is presented in Figure 5. The beams with the span of $3200 \mathrm{~mm}$ had rectangular crosssection of $120 \times 200 \mathrm{~mm}$. The HSC insert was located in the centre of a RC member in the compression zone and connected with bottom and top flexural reinforcement using $6 \mathrm{~mm}$ stirrups. The geometrical dimensions of HSC insert (the thickness and the length) were estimated assuming that insert cross-sections should be fully located in the compression zone of the considered innovative beams taking into account the assumptions for ULS design.

For this reason the neutral axis depth in the considered mid cross-section of the innovative beam (see Fig. 5) has been evaluated taking into account the deformational model of HSC, based on the rectangle parabolarelationship (Fig. 6).

The characteristic values of HSC are assumed in relation to the obtained concrete mean compressive strength

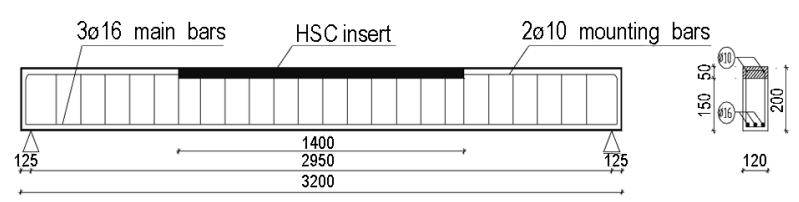

Fig. 5. The scheme of innovative full scale beam with the insert

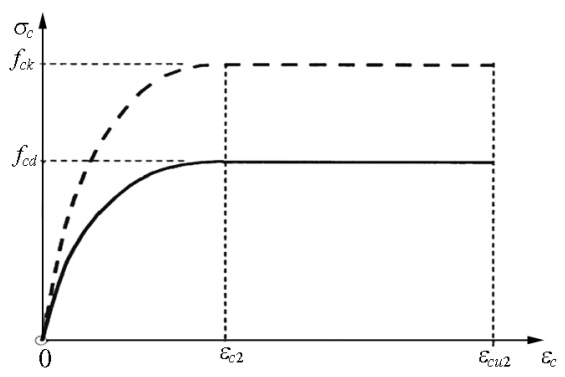

Fig. 6. Parabola - rectangle diagram for concrete in compression according to Model Code 2010 (CEB-FIB 2011) 
of $f_{c m}=108 \mathrm{MPa}$ : limit strains $\varepsilon_{c 2}=\varepsilon_{c \mathrm{cu} 2}=2.7 \%$ and the parabola exponent $n=1.3$, according to Model Code 2010 (CEB-FIB 2011).

For the assumed rectangular beam cross-section (with the constant width $b$ and effective depth $d$ ) the compressive stress block may be evaluated by the integration of stress diagram consisting of $n$-order parabola and rectangle in function of the $y$ distance from neutral axis depth $x$ to the given fibre under compression (Lapko, Jensen 2008):

$$
F_{c}=f_{c} b \int_{0}^{x}\left[1-\left(1-\frac{\varepsilon_{s u}}{\varepsilon_{c 2}(d-x)} y\right)^{n}\right] \mathrm{d} y,
$$

where $\varepsilon_{s u}$ denotes ultimate tensile strain in flexural steel.

For the assumed arrangement of flexural steel bars $3 \varnothing 16$ (with reinforcement ratio $\rho=2.9 \%$ ) the bilinear diagram for steel reinforcement RB500 with horizontal branch, assuming a yield strength of $f_{y}=500 \mathrm{MPa}$ of the steel type RB500.

For evaluation of internal bending moment in the light of ULS the following equation was used (Lapko, Jensen 2008):

$$
\begin{aligned}
& M_{R d}=\omega\left(1-\frac{1}{p(n+1)}\right) \\
&\left(1-\omega \frac{0,5 p(n+1)+\frac{1}{p(n+2)}-1}{p(n+1)}\right) b d^{2} f_{c},
\end{aligned}
$$

where: $w=d / x-$ dimensionless value of neutral axis depth in the cross-section of the beam, calculated from the Eqn (4):

$$
\omega=\frac{A_{s 1} f_{y}}{b d f_{c}} \frac{p(n+1)}{p(n+1)-1} .
$$

In the Eqns (3) and (4) the value $p$ denotes concrete compressive strain ratio $\varepsilon_{c 2} / \varepsilon_{c 2 u}$. For the assumed concrete compression strength $f_{c m}=108 \mathrm{MPa}-p=1.0$ and the order of parabola $n=1.3$, according to Model Code 2010 (CEB-FIB 2011).

Adopting the above Eqn (4) the value of dimensionless depth of compression zone w was calculated and equaled to 0.228 . Assuming that $d=172 \mathrm{~mm}$ the neutral axis depth $x$ in the critical section of the HSC insert is equal to:

$$
x=0.228 \cdot 172=39.2 \mathrm{~mm} .
$$

For the technological reasons it was assumed the thickness of the HSC insert is equal to $50>39.2 \mathrm{~mm}$. It means that the compression zone must be fully located in the cross section of the HSC insert. It was also assumed the length of the insert $1400 \mathrm{~mm}$.

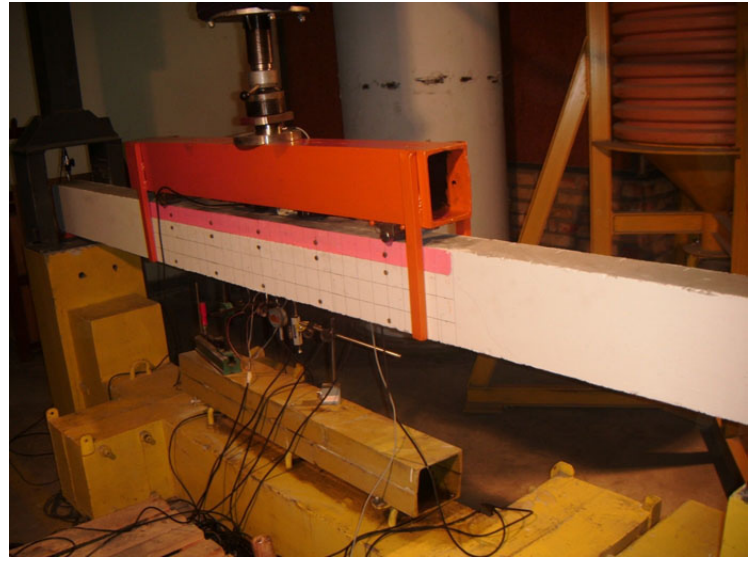

Fig. 7. View of full-scale beam with HSC insert before testing

On this basis, the critical internal bending moments taking into account the strengthening insert was calculated from Eqn (2) equaled to $M_{R}=48.9 \mathrm{kNm}$. Taking into account the four point system of loading during the experimental tests the theoretical critical $N_{R}$ load destroying the innovative $\mathrm{RH}$ beam type should be equal to $99.46 \mathrm{kN}$.

Internal forces in the cross- sections of homogeneous reference full scale beams, (without HSC inserts) were separately analyzed, using the same deformational model of normal strength concrete (see Fig. 7) on the basis of appropriate concrete strain characteristic $\varepsilon_{c 2}=$ $2 \%$ and $\varepsilon_{c u 2}=3.5 \%$ and the parabola exponent $n=2.0$.

\subsection{Results of short time tests of the beams}

Four series of full scale beams were prepared taking into account the results of the above dimensional analysis. Flexural steel bars arrangement (reinforcement ratios) were differed depending of the series of the beams. Stirrup spacing $(\varnothing 6 \mathrm{~mm})$ was constant along the shear span of the beams and equal to $120 \mathrm{~mm}$. The cross-section dimensions of full scale beams were equal to $120 \times 200 \mathrm{~mm}$. The HSC inserts with the thickness of $50 \mathrm{~mm}$ and $1400 \mathrm{~mm}$ in length were located in the centre of the compression zone of innovative beams (see Fig. 7).

In each series the following types of beams were prepared:

- S-RH series prototype beams (made of recycled aggregate concrete with the HSC insert);

- S-N series reference beams (natural aggregate concrete);

- S-R series reference beams (with coarse recycled aggregate concrete);

- S-H series reference beam (fully made of HSC).

The main data for concrete and reinforcement of the tested full-scale beams is presented in Table 3 .

Beam deflections were measured using inductive sensors produced by Megatron Muenchen with the measuring range of 25 and $50 \mathrm{~mm}$ and the accuracy of $0.001 \mathrm{~mm}$. Additionally, by using the DEMEC sensor the 
Table 3. The specifications and main characteristics of tested full-scale beams

\begin{tabular}{|c|c|c|c|c|}
\hline \multicolumn{2}{|c|}{$\begin{array}{c}\text { Series } \\
\text { specification }\end{array}$} & $\begin{array}{l}\text { The mean } \\
\text { strength of } \\
\text { concrete } f_{c m} \\
{[\mathrm{MPa}]}\end{array}$ & $\begin{array}{l}\text { Flexural } \\
\text { reinforcement }\end{array}$ & $\begin{array}{l}\text { Reinforcement } \\
\text { ratio [\%] }\end{array}$ \\
\hline \multirow{2}{*}{$\cdot \overrightarrow{\tilde{\omega}}$} & S1-N & 34.8 & \multirow[b]{2}{*}{$2 \varnothing 10+1 \varnothing 8$} & \multirow[b]{2}{*}{1.00} \\
\hline & S1-R & 32.5 & & \\
\hline \multirow{4}{*}{$\cdot \begin{array}{l}N \\
\mathscr{D} \\
\tilde{D} \\
\tilde{D}\end{array}$} & S2-N & 36.1 & \multirow{4}{*}{$2 \varnothing 14+1 \varnothing 12$} & \multirow{4}{*}{2.00} \\
\hline & S2-R & 36.7 & & \\
\hline & S2-RH & $34.7 / 112.0$ & & \\
\hline & S2-H & 111.6 & & \\
\hline \multirow{4}{*}{ m } & S3-N & 30.3 & \multirow{4}{*}{$3 \varnothing 16$} & \multirow{4}{*}{2.90} \\
\hline & S3-R & 33.8 & & \\
\hline & S3-RH & $33.4 / 112.0$ & & \\
\hline & S3-H & 111.6 & & \\
\hline 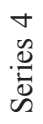 & $\begin{array}{l}\text { S4-RH } \\
\text { S4-H }\end{array}$ & $\begin{array}{l}34.7 \\
111.6\end{array}$ & $2 \varnothing 20+1 \varnothing 16$ & 3.97 \\
\hline & S4-H & 111.6 & $2020+1016$ & 3.97 \\
\hline
\end{tabular}

concrete strains were measured in several vertical cross sections and at several levels of the depth of the beam cross-sections. The experimental relationships: applied load - the tested S-3 series beams deflection (reinforcement ratio of $2.9 \%$ ) are shown in Figure 8.

The experimental tests conducted on full-scale innovative beams clearly showed that application of HSC inserts significantly increase flexural stiffness of such beams. For example, the average beam deflections of S2-RH series (with reinforcement ratio of 2.0\%) under the load of $55 \mathrm{kN}$ were lesser by about $20 \%$, compared to the homogenous reference beams made of S2-R type recycled aggregate concrete. The innovative S3-RH Series beams (reinforcement ratio of $2.9 \%$ ), at a load of $75 \mathrm{kN}$ showed mean deflections lesser by about $40 \%$, compared to the reference beams fully made of RAC.

Comparing the deflection results of the reference beams, the recycled aggregate concrete S2-R series

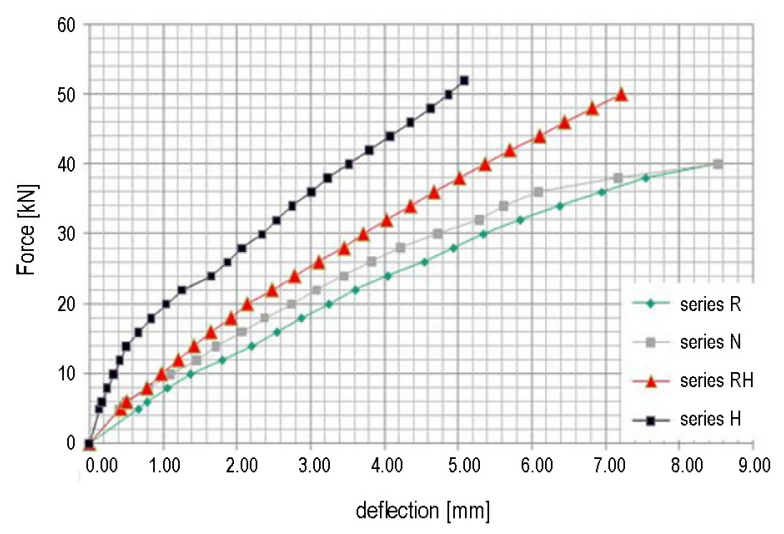

Fig. 8. Diagrams of mean deflection values versus applied load for full-scale beams of S3 series

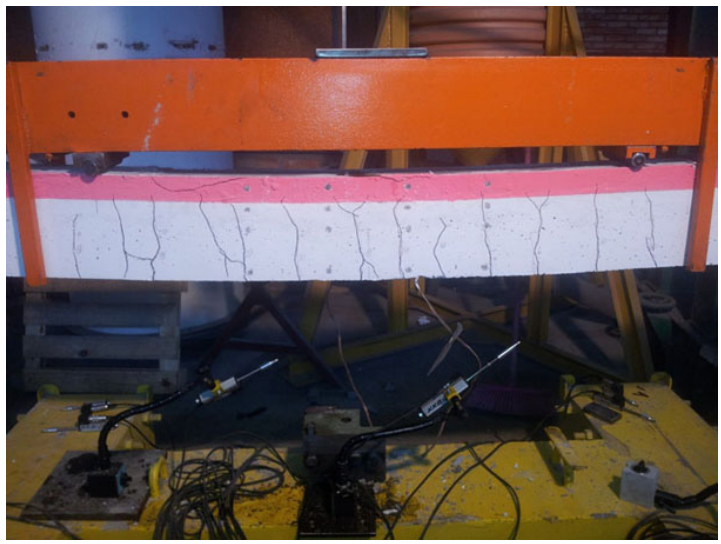

Fig. 9. Cracking of tested full-scale innovative beam with HSC insert showing model of flexural failure

beams showed mean deflection (at loading force $55 \mathrm{kN}$ ) about $15 \%$ larger compared to the beam S2-N made of natural aggregate concrete. The S3-R Series beam (with reinforcement ratio of $2.9 \%$ ) at a force of $75 \mathrm{kN}$ showed nearly $11 \%$ greater deflection than $\mathrm{S} 3-\mathrm{N}$ beams.

The behavior of failure of tested innovative fullscale $\mathrm{S} 3$ Series beam (S3-RH) is shown in Figure 9. It is clearly visible that the flexural cracks cross the contact surface between the insert HSC (pink layer) and recycled aggregate concrete (white part of the beam) without any slip.

The concrete compressive strains in the compressive and tensile zone were simultaneously registered using inductive sensors (see Fig. 10).

The mean concrete strains on the top compressive fibers of the tested full-scale beams are presented in the Table 4. The quantitative comparison of concrete compressive strain values registered for the tested S2 Series beams of presented in the Table 5 for the two levels of loading forces: $30 \mathrm{kN}$ and $40 \mathrm{kN}$.

The test results of tested beam deflections shown in Figure 9 and the results of measured compressive concrete strains presented in the Tables 4 and 5 clearly show the effectiveness of the use of strengthening HSC inserts,

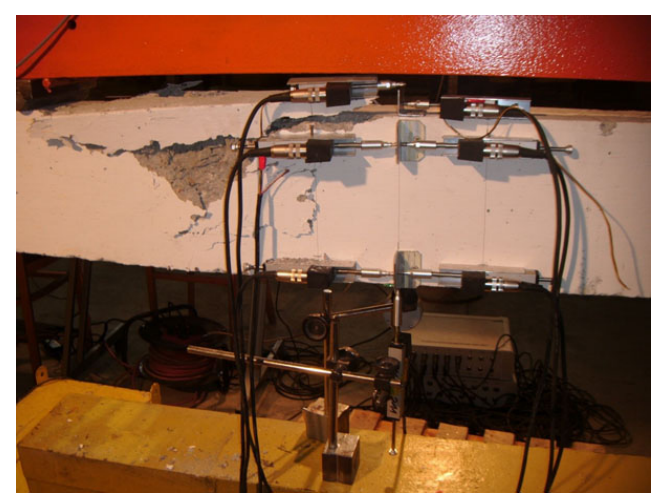

Fig. 10. Registration of concrete strains using inductive sensors for tested reference beam without strengthening insert, showing the model of failure of reference beam made of RAC 
Table 4. The mean values of compressive concrete strains on the top surface of tested full-scale beams of Series S3

\begin{tabular}{cccc}
\hline \multirow{2}{*}{$\begin{array}{c}\text { Applied } \\
\text { load [kN] }\end{array}$} & \multicolumn{3}{c}{$\begin{array}{c}\text { Mean values of concrete strains in top fibre } \\
\text { of tested beams [\%o] }\end{array}$} \\
\cline { 2 - 4 } & S3-N & S3-R & S3-RH \\
\hline 0 & 0.00 & 0.00 & 0.00 \\
5 & 0.24 & 0.21 & 0.06 \\
10 & 0.35 & 0.31 & 0.12 \\
15 & 0.42 & 0.43 & 0.15 \\
20 & 0.53 & 0.56 & 0.19 \\
25 & 0.69 & 0.72 & 0.24 \\
30 & 0.83 & 0.86 & 0.28 \\
35 & 0.95 & 1.04 & 0.33 \\
40 & 1.09 & 1.19 & 0.37 \\
45 & 1.26 & 1.36 & 0.41 \\
50 & 1.41 & 1.41 & 0.48 \\
55 & 1.58 & 1.78 & 0.52 \\
60 & 1.76 & 1.97 & 0.56 \\
65 & 1.97 & 2.23 & 0.61 \\
70 & 2.21 & 2.49 & 0.65 \\
75 & 2.51 & 2.79 & 0.70 \\
\hline
\end{tabular}

Table 5. Qualitative comparison of concrete compressive strains [\%o] registered for tested full-scale S2 Series beams

\begin{tabular}{|c|c|c|c|c|}
\hline Beam Types & $\begin{array}{c}\text { Load } \\
\text { Strains } \\
\text { diff }\end{array}$ & $\begin{array}{l}\mathrm{kN}] \\
\text { and the } \\
\text { ces }\end{array}$ & $\begin{array}{r}\text { Loa } \\
\text { Strains } \\
\text { dif }\end{array}$ & $\begin{array}{l}\mathrm{kN}] \\
\text { and the } \\
\text { ces }\end{array}$ \\
\hline Beam S2-RH & 0.58 & \multirow{2}{*}{0.74} & 0.81 & \multirow{2}{*}{0.73} \\
\hline Beam S2-N & 0.78 & & 1.11 & \\
\hline Beam S2-RH & 0,58 & \multirow{2}{*}{0.55} & 0,81 & \multirow{2}{*}{0.58} \\
\hline Beam S2-R & 1.06 & & 1.39 & \\
\hline Beam S2-RH & 0.58 & \multirow{2}{*}{1.18} & 0.81 & \multirow{2}{*}{1.27} \\
\hline Beam S2- H & 0.49 & & 0.64 & \\
\hline
\end{tabular}

reducing deflections and compressive strains and increasing overall stiffness of the innovative beams, compared to the $\mathrm{R}$ and $\mathrm{N}$ type reference beams.

The short time tests were conducted till the failure. In the Table 6 the mean values of the critical loads for tested S2 and S3 Series beams are presented. The results clearly showed that the innovative S-RH type beams with HSC inserts failed in flexure at significantly higher critical load, compared to the S-N reference beams (made of natural aggregate concrete) and S-R beams (made of $\mathrm{RAC}$ ).

For example, the S3-RH beams revealed increase of flexural capacity about $35 \%$ higher compared to the reference S3-R type beams fully made of RAC.

Mean values of critical loads were almost equal or even a little higher than for the reference S-H Series beams fully made of HSC.
Table 6. Average values of applied critical load for the fullscale beams of S-2 and S-3 Series

\begin{tabular}{ccccc}
\hline \multirow{2}{*}{$\begin{array}{c}\text { Beam } \\
\text { series }\end{array}$} & \multicolumn{4}{c}{ Average values of critical load $\mathrm{N}_{R}[\mathrm{kN}]$} \\
\cline { 2 - 5 } & N Type & R Type & RH Type & H Type \\
\hline S-2 Series & 57.2 & 55.1 & 63.2 & 70.1 \\
\hline S-3 Series & 82.25 & 77.7 & 104.6 & 98.4 \\
\hline
\end{tabular}

As expected, the reference beams made of RAC showed a little less flexural capacity than reference beams made of natural aggregate concrete. The differences were between $4 \%$ for the S-2 Series to $5.5 \%$ for the beam S-3.

\subsection{Long term effects in the innovative beams}

As part of the research the two reinforced concrete beams (with the span of $3200 \mathrm{~mm}$ and cross-section of $120 \times 200 \mathrm{~mm}$ ) were prepared and tested as free supported beams under long term load. The RH type beam was made of recycled aggregate concrete with HSC insert while the R type beam was made fully of RAC (Fig. 11).

Flexural reinforcement of the beams was made of $3 \varnothing 16$ bars (bottom) and $2 \varnothing 10$ bars (top) made of RB500 class of steel. The stirrups were made of plain bars with the diameter of $\varnothing 6 \mathrm{~mm}$.

The constant value of load equal to $40 \mathrm{kN}$ (about $40 \%$ of critical load) was subjected in the form of two concentrate forces located at one-third of beam span. Long-term beam deflections and concrete strains at several levels of beam sections were measured every day during the period of 150 days.

The time dependent deflection diagrams for the two tested beams are presented in Figure 12. It is clearly seen that the deflections of reference beam fully made of recycled aggregate concrete are visible larger during all the time of loading in comparison with the beam with HSC insert strengthening. The differences between deflections of the two beams after 150 days of testing were about $31 \%$.

\section{FEM analysis of the innovative full scale beams}

The non-linear FEM analysis was elaborated for the experimentally tested innovative full-scale (S3-RH type)

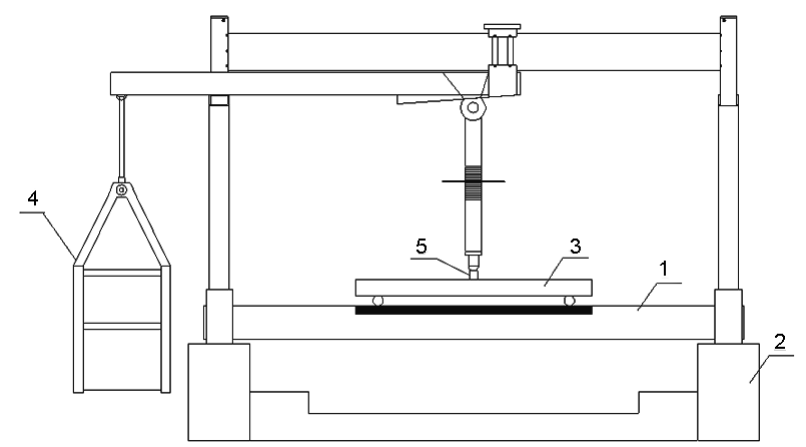

Fig. 11. The view of the test stand showing the method of loading of beams: $(1$ - reinforced concrete beam, 2 - test stand, 3 - steel loading beam, 4 - loading basket, 5 - dynamometers) 


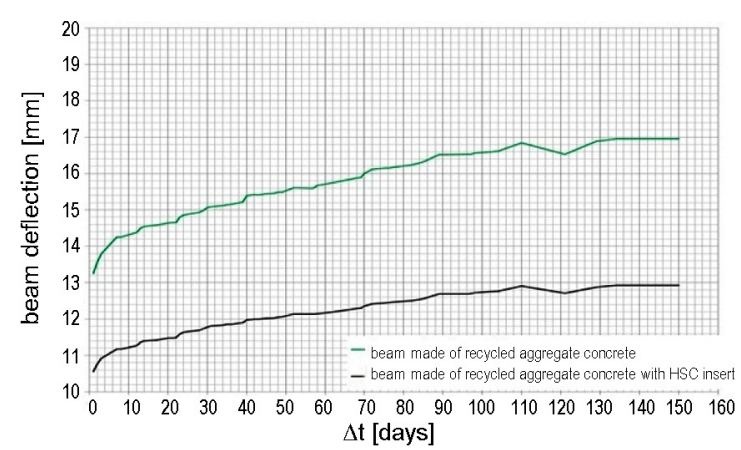

Fig. 12. Long-term deflections registered for the innovative beam (grey line) and for reference beam (green line)

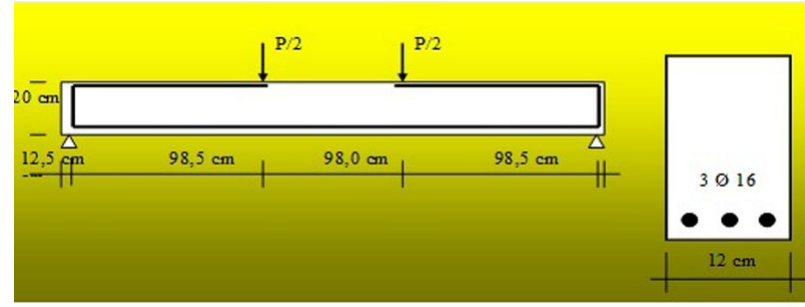

Fig. 13. Flexural reinforcement and the load for full scale beam assumed in non-linear FEM analysis

beam with the strengthening HSC insert showed in Figure 13 (beam cross-section of $120 \times 200 \mathrm{~mm}$ and flexural bottom reinforcement $3 ø 16 \mathrm{~mm}$ ).

For comparison the homogenous reference beams (fully made of recycled aggregate concrete) have also been analyzed. The FEM analyses simulated the four point loading system were carried out using the DIANA computer program, as an implementation of the Finite Element Method. The model of beams was formulated using 4-node finite elements with constant thickness working in plan stress state.

The assumptions for non-linear behavior of concrete were taken into account based on the Rankine/DruckerPrager model (Feenstra 1993). In the numerical tests the commonly known Newton-Raphson algorithm assuming $5 \%$ increase of loading forces in 20 steps was used. The critical load for the analyzed full-scale beams, equal to $160 \mathrm{kN}$, was assumed.

The material characteristics were assumed identical as for experimentally tested full-scale beams of S3 Series (see Table 3).

For the FEM analysis a four nodal finite elements with the dimensions of $10 \times 10 \mathrm{~mm}$ (total number of 6400 elements) were assumed in the plan state of stresses.

Reinforcing steel flexural bars of analyzed beams were modelled by specialized REBAR type finite elements.

The maps of stresses in the concrete of two types of analyzed beams are presented in Figure 14. The maps illustrate the flattening of the stresses in the compression zone, which indicates a "runoff" of the compressive stresses, depending of the type of analyzed beam.
It can be clearly seen that in the $\mathrm{R}$ type reference beam fully made of recycled concrete (Fig. 14a) the compressive stress field is distributed in the wide area of the central beam sections, whereas the HSC insert of innovative beam (Fig. 14b) limited the "runoff" of compressive stresses in the thin area of the insert. At the interface between HSC insert and RAC (see Fig. 14b) there no visible concentrations of compressive stresses appear, because the strengthening insert is fully located in the compression zone.

Figure 15 represents diagrams of beam deflections (vertical axis) versus load factor (horizontal axis) of the two analyzed types of beams: innovative beam (RH type) and homogeneous $\mathrm{R}$ type reference beam).

The $p$ load factor indicates the ratio of applied actual load to the critical load assumed in the FEM analyzes.

The diagrams of deflections clearly confirmed the increased stiffness of innovative beams with the HSC inserts. For the load factor $p=0.5$ the deflection of $\mathrm{RH}$ type beam equals $17.5 \mathrm{~mm}$ and for the same factor the deflection of $\mathrm{R}$ type reference beam equaled to $22.5 \mathrm{~mm}$. The difference is about $29 \%$.

Almost the same results were obtained from the experimental tests conducted for full-scale beams, described in Section 2.2.

The simulation of FEM behaviour of tested $\mathrm{R}$ type beam (fully made of recycled aggregate concrete) showed that this beam was destroyed under the $\mathrm{P}=88 \mathrm{kN}$ load, whereas for the innovative RH beam (with the HSC insert) the destructive load was equal to about $120 \mathrm{kN}$.

(a)

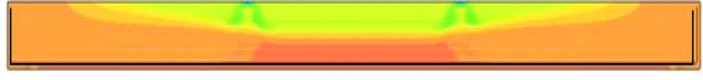

(b)

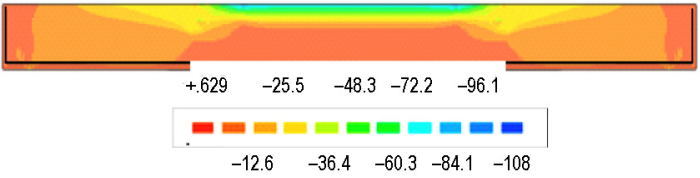

Fig. 14. Nonlinear FEM analysis of full-scale beams - concrete stress distribution [MPa]: a) for R type reference beams; b) for innovative RH type beams (with HSC insert)

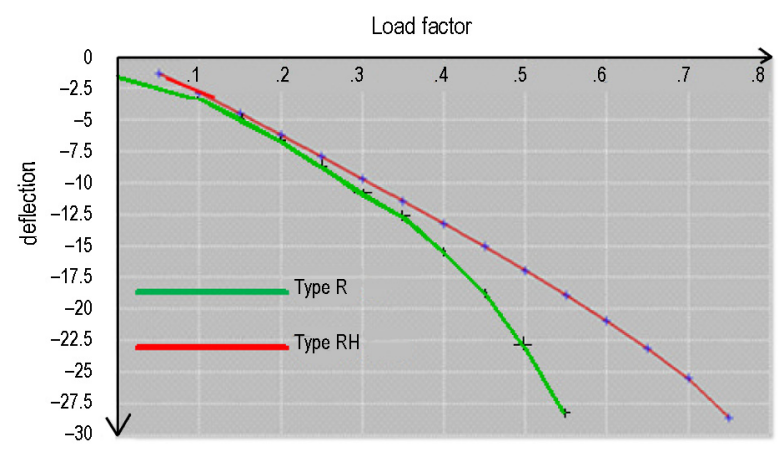

Fig. 15. Diagrams of deflections in the half span of analyzed beams: reference beam ( $\mathrm{R}$ type) and innovative beam ( $\mathrm{RH}$ type): vertical axis - beam deflections [mm], horizontal axis $p$ load factor, as the ratio of actual load to assumed critical load) 
It means that the increase of the innovative beams theoretical flexural capacity was about $36 \%$, compared to the homogenous reference beam (R type) fully made of recycled aggregate concrete.

It means that the increase of theoretical flexural capacity for the innovative beam was about to $36 \%$, compared to the homogenous reference beam (R type) fully made of recycled aggregate concrete.

Additional FEM simulation using the DIANA computer Program for long term loads were performed for the innovative RH type beam (shown in Fig. 13), taking into account the effects of creep and shrinkage in the period of 150 days. In this analysis it was assumed that constant load level equal to $40 \mathrm{kN}$ (about $40 \%$ of critical load). The same FEM analysis was also performed for the R type reference beam (fully made of recycled aggregate concrete).

This analysis proved it was found that the long term phenomena in concrete for the innovative beams increased the concrete strains and deflections, however the increment ratio was similar compared to the reference beam made of RAC without reinforced HSC inserts.

\section{Conclusions}

1. The results of experimental tests for the model and full-scale RC beams as well as FEM analyses clearly shows the positive effects of the strengthening of the beams made of RAC with the HSC insert compared to homogenous reference beams fully made of recycled aggregate concrete or made of concrete with natural aggregate of similar class.

2. In the analyzed cases the flexural capacities for innovative beams with HSC inserts compared to the homogenous reference beams was larger by $20 \%$ to $36 \%$. This effect was greater for the beams with larger flexural reinforcement ratio.

3. The use of HSC inserts in the compressive zone of RC beams made of RAC significantly increased flexural stiffness influencing strains, deflections and the width of cracks. The innovative beams made of RAC strengthened by the use of HSC inserts revealed lesser deflections in the range of $20-40 \%$ and concrete compressive strains in the range of $50 \%$ compared to the reference beams fully made of RAC.

4. The studies confirmed the effectiveness of the proposed concept of strengthening of RC precast concrete members made of recycled aggregate concrete with the strengthening HSC inserts, located in the most stressed compression zone.

\section{Acknowledgements}

The authors are grateful for the financial support provided by for the National Centre of Research and Development (NCBR) in the frame of Grant NCBiR NR04-0012$10 / 2010$.

\section{References}

Ajdukiewicz, A.; Kliszczewicz, A. 2007. Comparative tests of beams and columns made of recycled aggregate concrete and natural aggregate concrete, Journal of Advanced Concrete Technology 5(2): 259-273.

http://dx.doi.org/10.3151/jact.5.259

Ajdukiewicz, A.; Kliszczewicz, A. 2012. Properties of structural concretes with the recycling aggregates, in The $58^{\text {th }}$ National Scientific Conference, 2012, Rzeszów-Krynica, Poland, 173-180 (in Polish).

Cassuccio, M.; Torrijos, M. C.; Giacco, G.; Zerbino, R. 2008. Failure mechanism of recycling aggregate concrete, Construction and Building Materials 22(7): 1500-1506. http://dx.doi.org/10.1016/j.conbuildmat.2007.03.032

CEB-FIB. 2011. Model Code 2010. Final Draft. Vol. 1. 350 p.

Domski, J.; Katzer, J. 2013. Load-deflection characteristic of fibre concrete based on waste ceramic aggregate, Annual Set The Environment Protection 15: 213-230.

Feenstra, P. H. 1993. Computational aspects of biaxial stress in plain and reinforced concrete: $\mathrm{PhD}$ thesis. Delft University of Technology, Delft, Netherlands.

Gilbert, R. I.; Kilpatrick, A. 2011. Improved prediction of the long-term deflections of reinforced concrete flexural members, in Proc. of Fib Symposium, 2011, Prague, Czech Republic. 2011, Session 1-5: New Model Code, 1-9.

Grygo, R.; Chyży, T.; Lapko, A. 2011. Modeling of local strengthening of $\mathrm{RC}$ beams made of recycled aggregate concrete using HPC, in International Conference on Engineering (UBI 2011), 28-30 November 2011, University of Beira Interior, Covilhã, Portugal. 6 p.

Jeske, U.; Buchgeister, J.; Schebek, L.; Weil, M. 2004. Beton mit rezyklierter Gesteinskörnung - eine Ökobilanz, Nachrichten - Forschungszentrum Karlsruhe Jahrg 36(4): 219 224. (in German).

Ho, N.; Lee, Y.; Lim, W.; Zayed, T.; Chew, K.; Low, G.; Ting, S. 2013. Efficient utilization of recycled concrete aggregate in structural concrete, Journal of Materials in Civil Engineering 25(3): 318-327. http://dx.doi.org/10.1061/(ASCE)MT.1943-5533.0000587

Lapko, A.; Grygo, R. 2013. Studies of RC beams made of recycling aggregate concrete strengthening with of the HSC-HPC inclusion, Procedia Engineering 57: 678-686. http://dx.doi.org/10.1016/j.proeng.2013.04.086

Lapko, A.; Grygo, R. 2011. Flexural capacity and deformability of RC beams with the use of recycled aggregate concrete, in Sbornik Naučnyh Trudov Instituta Stroitel'stva $i$ Arhitektury. Moskva: MGSU, 3: 53-57.

Lapko, A.; Grygo, R. 2010. Long term deformations of recycled aggregate concrete (RAC) beams made of recycled concrete, in Proc. of the $10^{\text {th }}$ International Conference "Modern Building Materials, Structures and Techniques", 19-21 May 2010, Vilnius, Lithuania, 367-372.

Lapko, A.; Grygo, R.; Sadowska-Buraczewska, B. 2009. Precast concrete structural member. Home Patent Claim no. P 388540, 16 ${ }^{\text {th }}$ June 2009 (in Polish).

Lapko, A.; Jensen, B. C. 2008. Podstawy projektowania i algorytmy obliczeń konstrukcji żelbetowych [Basics of design and algorithms of calculation of RC structures]. Warsaw: ARKADY. 432 p. (in Polish).

Lapko, A.; Sadowska Buraczewska, B.; Tomaszewicz, A. 2005. Experimental and numerical analysis of flexural composite beams with partial use of high strength/high performance concrete, Journal of Civil Engineering and Management 11(2): 115-120.

http://dx.doi.org/10.1080/13923730.2005.9636340

Limbachiva, M. C.; Koulouris, A.; Roberts, J. J.; Fried, A. N. 2004. Performance of recycled aggregate concrete, in Proc. of the International RILEM Symposium on Environ- 
ment - Conscious Materials and Systems for Sustainable Development, 2004, 127-136.

Maruyama, I.; Sogo, M.; Sogabe, T. 2004. Flexural properties of reinforced recycled concrete beams, in Proc. of Conference on the Use of Recycled Materials in Building and Structures, 2004, Barcelona, Spain. 10 p.

Malešev, M.; Radonjanin, V.; Marinković, S. 2010. Recycled concrete as aggregate for structural concrete production, Sustainability 2(5): 1204-1225. http://dx.doi.org/10.3390/su2051204

Murali, G.; Vivek Vardhan, C. M.; Rajan, G.; Janani, G. J.; Shifu Jajan, N.; Ramya Sri, R. 2012. Experimental study on recycled aggregate concrete, International Journal of Engineering Research and Applications (IJERA) 2(2): 407-410.

Rahal, K. 2007. Mechanical properties of concrete with recycled coarse aggregate, Building and Environment 42(1): 407-415. http://dx.doi.org/10.1016/j.buildenv.2005.07.033

RILEM. 1994. RILEM Recommendation: specifications for concrete with recycled aggregate, Materials and Structures 27: 557-559. http://dx.doi.org/10.1007/BF02473217
Roos, F. 2002. Ein Beitrag zur Bemessung von Beton mit Zuschlag aus rezyklierter Gesteinskornung nach DIN 1045-1. Berichte aus dem Konstruktiven Ingenieurbau, München: Technische Universität München. 186 p.

Sagoe-Crentsil, K. K.; Brown, T.; Taylor, A. H. 2001. Performance of concrete made with commercially produced coarse recycled concrete aggregate, Cement and Concrete Research 31: 707-712. http://dx.doi.org/10.1016/S0008-8846(00)00476-2

Shayan, A.; Xu, A. 2003. Performance and properties of structural concrete made with recycled concrete aggregate, $A C I$ Structural Journal 100(5): 371-380.

Yadav, S. R.; Pathak, S. R., 2009. Use of recycled concrete aggregate in making concrete - an overview, in The $34^{\text {th }}$ Conference on Our World in Concrete \& Structures, 1618 August 2009, Singapore. 9 p.

Xiao, J.; Li, J.; Zhang, C. 2007. On statistical characteristics of the compressive strength of recycled aggregate concrete, Structural Concrete 6(4): 149-153.

http://dx.doi.org/10.1680/stco.2005.6.4.149

Andrzej LAPKO. Professor (deceased), many years worked at the Bialystok University of Technology as the head of Building Structures Department. Member of Civil and Water Engineering Committee of Polish Academy of Science, president of Committee of Science of Polish Association of Civil Engineers and Technicians, the Polish delegate of fib. His research interest concerned reinforced concrete and fiber reinforced concrete structures, particularly the structures made of recycled aggregate concrete and concrete structures reinforced with nonmetallic rebar.

Robert GRYGO. PhD of Construction Engineering, Dept of Civil and Environmental Engineering, Bialystok University of Technology, Research interests: reinforced concrete structures, environmental protection, analysis and design of reinforced concrete structures with the use of recycled aggregate concrete, application of high-strength concrete. 